\title{
Preferences of the Teachers in Employing Revised Blooms Taxonomy in their
}

\author{
Instructions \\ * Dr. Rani Gul, Assistant Professor (Corresponding Author) \\ ** Shazia Kanwal, Principal \\ *** Dr. Sadia Suleman Khan, Assistant Professor
}

\begin{abstract}
In the present study teachers' preferences in their instructional methods were integrated with the revised model of blooms taxonomy to seek out how much they are incorporating the instructional approaches linked with all six domains of revised bloom taxonomy. The study has also sought out the impact of teachers' qualifications and teaching experiences on teachers' preferences for these instructional approaches. The findings show that teachers often use the higher-order domain, while other large domains were found on average. The academic qualification and teaching experience have not found significantly correlated with these instructional approaches. The study suggests that teachers spend their time designing teaching methodologies that can promote higher-level thought skills for students, to improve their student learning qualifications. Teachers can adopt methodologies to enable their students to think and discuss the content, encourage discussion, stimulate students to find information themselves, create cause and effect, encourage student opinion, insert several characters and map concepts in the real world. Besides, additional teaching support can also be expected from educational departments and administrations.
\end{abstract}

Keywords: Blooms Taxonomy, Instructional approaches, Cognitive skills, Critical thinking, Students learning.

\section{Introduction}

The nature of today's social and educational environments is apparent in every classroom in different student populations. This diversity has been supported by the inclusive schools' movement which promotes the inclusion of students' potential learning and their problems in regular classrooms (Foreman, 2001; Stainback, \& Stainback, 1996).

Teaching in 21 centuries considered the need for teaching approaches that understand the different strengths of students and their weaknesses, and provide flexibility in content, processes, and products to meet the learning needs of the individual students. There have been significant efforts in the last decade to improve the critical thinking skills of students by increasing student participation (Handelsman et al. 2004).

Research shows, however, that both pre-service and service teachers are unwilling or unable to provide diversity in their classrooms for their students in the catering of their cognitive learning needs (Tomlinson et al., 1997). Literature affirms that efficient course design is important to match instructional practices and approaches with learning outcomes (Wiggins and McTighe, 1998; Sundberg, 2002; Ebert-May et al., 2003; Fink, 2003; Tanner and Allen, 2004, Bissell and Lemons, 2006). The cognitive issue of exam questions can also greatly influence students' research and teachers ' teaching methods (Gardiner, 1993; Scouller, 1998). Students are well motivated by their exams.

Blooms' updated taxonomy of cognitive education priorities (RBT) provides a dynamic hierarchy that orders cognitive processes from basic memorialization to higher-order critical and imaginative thought. Dr. Benjamin Bloom and many other psychologists provided recommendations in 1956 to establish educational objectives. Known as the Taxonomy of Bloom. In 2001, his stages were reworked and revised by educational and cognitive psychologists.

\footnotetext{
* Department of Education, University of Malakand, Chakdara, KP Email: dr.rani27@ gmail.com

** Elementary and Secondary Education Department, KP Email: shaziamd09@ gmail.com

*** Department of Education, SBKWU, Quetta, Balochistan Email: ssuleman_khan786@yahoo.com
} 
The revised taxonomy simplifies teachers' writing goals. The framework builds on itself, with minimal understanding on the first level. Blooms Taxonomy is a series of three graded models for organizing educational learning goals into levels of complicity and specificity. The purpose of the framework is to identify and distinguish diverse levels of understanding and cognition of human beings. According to this taxonomy, educational goals are divided into three, (a) Effective domain (b) Psycho-motor domain c) Cognitive domain. The six levels (revised) for the cognitive domain (from simple to complex thinking) are Remember, Understand, Apply, Analyze, Evaluate, and create (Anderson, 1999; Anderson \& Krathwohl, 2001).

The taxonomy of Bloom mainly focuses on teachers to establish their goals for training. There is no question that Bloom has a tremendous impact on educational thought and training around the world (Anderson, 2001; Anderson \& Krathwohl, 2006). Educational goals have been considerably affected. The goal of this study was to gain a profound understanding of how often teachers follow the six dimensions of RBT in their instructions to allow students to focus on the skills and to demonstrate what they understand across various intellectual fields at the same level of cognitive sophistication or different levels.

The Revised Bloom's Taxonomy is an even better tool for the needs of today's professors. It remains easy to understand the cumulation hierarchic structure, which consists of 6 divisions, each one of which involves the achievement of previous skill. This includes a classification of intellectual activity rates, which are essential for learning. Bloom's Taxonomy included the method of thinking calculation. "The framework of the updated Taxonomic Matrix offers a straightforward and descriptive description of the aligning expectations and educational objectives, priorities, goods, and activities" (Krathwohl, 2002). "Today's teachers must make tough decisions about how to spend their classroom time. Clear alignment of educational objectives with local, state, and national standards is a necessity (Krathwohl, 2002, p.12).

\section{Theoretical Framework}

For the theoretical framework, six cognitive domains of revised blooms taxonomy and their related instructional approaches are discussed as

Blooms Model Higher Order Thinking Category and Their Related Instructional Strategies

i. Analyze: decompose materials into their pieces to analyze them. Knowing, learning.

Case Studies Simulations, Discussion, Labs \& Graphical Organizers. (Computer-based, models, part-task training, roles). The instructional also includes structuring the concept as cause and effect, let the students decide, let the students think and argue, learn through observation and senses, making a connection between topics.

ii. Evaluate: Judgment of material interest based on personal values/opinions or other requirements. Evaluation of content to decide if it fulfills a specific purpose. Internal (organization; specified by the student) or external (for the purpose; given to the student) may be the criterion. Demonstrate work evaluation process based on criteria, Case Studies - Large group debates on procedures suitability, performance, Debates are some of the teaching methods that fall into this aspect. The instructional also includes asking students opinions, providing books, giving a stimulative environment where things are within their touch and sight, teaching in a natural setting, connecting topics with real-world examples, etc.

iii. $\quad$ Create: The use of modern and innovative knowledge and skills programs.

Research / Labs, Strategy development, various case studies - classroom discussions or small groups that gather relevant knowledge, prepare to deal with ongoing issues, meetings with experts, expert discussions. The instructional also includes Using emotions, Insert Multiple characters, teach in the form of a story, and bring the topic in the creative form e.g. concept mapping, allow students to use their stuff for learning content. Blooms Model Lower Order Thinking and Their Related Instructional Strategies

iv. Remember: Remembering and remembering knowledge previously known. This is the Best things. Action verbs: identity, define, state, name, order, list, recognition, the basic level of understanding. Examples: Cost limit. Identify a customer's location for items in a store. The instructional also includes help students to understand how everything they learn is related to recap the concepts after a lecture, provide time to students to close their eyes and 
visualize, in resource people who offer additional perspective on a topic, show videos to accompany material being learned.

v. Understand: Understand the meaning of details and resources. Teaching methods Include reading, arranging the images, presentation, and discussion. The instructional also includes Appreciate students to ask questions, respond to instruction by gestures, share questions, answers, and information with other students, student groups to work cooperatively.

vi. Apply: The use of knowledge and resources to solve or respond to new problems.

Situations with a single or best reaction. Explain problem-solving (case studies, text problems, examples, implementation of codes, laws or hypotheses, explain procedures, work in a range of contexts. Case Studies. The instructional also includes helping students to do projects, assigned activities that need interaction with the community, public speaking, demonstrate understanding by constructing a model of it, making crafts out of natural materials, act out on the learned material.

\section{Literature Review}

Applications of Revised Bloom Taxonomy in the field of education

In nearly all circumstances, Bloom's Taxonomy can prove beneficial in moving a group of students through an organized learning process. The author explains the use of Bloom's updated Taxonomy to prepare and implement an integrated English and History course called "West Culture," in a review of (Ferruson, 2002). The taxonomy offered teachers a shared language for tradition and discussion of state expectations from two different topic fields. It also enabled them to understand the overlap and growth of conceptual and procedural information in their fields. Besides, the revised taxonomy table gave the history teachers and English teachers a new outlook on evaluations and allowed them to create tasks and projects for students to be able to work at the most intricate levels of thought (Ferguson, 2002).

The updated taxonomy also includes a particular verb and product relation to each stage of the cognitive process aspect. Nevertheless, with its 19 subcategories and two-dimensional structure, the fitting of a particular verb or object to a certain level is more straightforward and less complicated. The revised taxonomy thus provides teachers with an even better instrument for helping to build their lesson plans.

As discussed earlier, Bloom's taxonomy has generated educational principles such as highlevel and low-level thought. Facility management, innovative and critical thought, and more recently incorporation of technology (Noble, 2004).

\section{Applications of Revised Bloom's taxonomy for Teachers}

The aim of an educator with the taxonomy of Bloom is to enable students to think more in order through the building up of cognitive skills at a lower level. In the present research, pupils explore how pathways of teaching are in line with cognitive learning objectives outlined in BT, and how Bloom's taxonomy can be integrated into broader pathways.

An instructor would like to use Bloom's taxonomy for many reasons. It can be used initially to increase the comprehension of the learning process. Teachers can see and understand dynamic cognitive development and how knowledge in lower levels can become a higher order of thought (e.g., a student can use his expertise to remember information and consider previous problems). With this concept, content can be prioritized and lessons arranged to optimize the time of instruction. For example, before the introduction of higher skills (e.g., relationship analysis), lower levels (e.g., memorization of factual knowledge) can be developed. A confusing set of standards and requirements often faces current educators. Current educators. Bloom's taxonomy provides a framework for splitting these requirements into usable parts that can be used to organize everyday lesson plans and effectively compare it to their own class goals. Just as different rates require various methods of delivery of instruction, different assessment methods are also required. Bloom's taxonomy can be used as a checklist to guarantee that the assessment methods for every level of the domain are validated and compatible with the correct lessons and methods. The taxonomy also promotes the continuity between methods of assessment and content and education, as well as the identification of vulnerable areas.

In addition to writing goals, Bloom's taxonomy also helps students to assess understanding concepts. Knowing and exploring the various levels of students helps you to transfer them from a 
simple level to a more complex level. If you don't hit all levels, it may be time for you to go back and focus a little on your curriculum and restructure your course.

\section{Research Questions}

1. How often teachers incorporate the six cognitive dimensions of Bloom taxonomy in their instructions?

2. To what extent teachers' professional qualification and teaching experience affect the incorporation of bloom taxonomy in their Instructional methods?

\section{Methods and Materials}

\section{Participants and setting:}

For this descriptive research study, The Population of the study consisted of secondary school teachers. There are741 Secondary School Teachers (SST) (434 males and 307 females) working in secondary schools in district Peshawar (ASC, 2017-2018). Due to time constraint and limited financial resources, A sample size of 259 SST serving in different rural and urban areas secondary schools was taken, that was proportional (35\%) to the entire population size. Similarly, 253 which included 148 male and 108 female SST participated in the study.

\section{Data Collection Instrument}

Four-point liker scale questionnaire consisted of 36 teaching strategies for all six (06) domains of blooms taxonomy was used to collect the required information. Teachers adopted instructional methods were classified in two main categories (I) Blooms Model higher-order thinking category (Analyze, Evaluate and Create) and (ii) Blooms Model lower-order thinking (Remember, Understand and Apply

For each domain, there were 6 statements which were ranked as 1 for infrequently, 2 for sometimes, 3 for frequently, 4 for always. The details of these 36 instructional strategies' are given in the results section. The questionnaire was prepared by the researcher taking help from the existing available literature on revised blooms taxonomy. Before administration, the questionnaire was tested for validity and reliability by some of the study participants, educational professors, and educational psychologists. The Cronbach alpha for the mean of all six domains was found .862. The collected data was analyzed using descriptive statistics (Frequency, Mean, and Standard Deviation) and Pearson Correlation Coefficient

\section{Results}

Statistical Analysis of the Instructional Approaches Associated With Blooms Taxonomy Higher Order Thinking

Table 1: Descriptive statistics of instructional approaches associated with "Analyze" dimension

\begin{tabular}{|c|c|c|c|c|c|c|}
\hline \multirow[b]{2}{*}{ Teaching Methods Related to Analyzed Dimension } & \multicolumn{4}{|c|}{ Frequency } & \multirow[b]{2}{*}{ Mean } & \multirow{2}{*}{$\begin{array}{l}\text { Std. } \\
\text { Dev }\end{array}$} \\
\hline & In free & Some & Freq & Alway & & \\
\hline Making connections between the topics & 3 & 33 & 72 & 145 & .048 & .760 \\
\hline $\begin{array}{l}\text { Compelling students to learn through observation and } \\
\text { senses. }\end{array}$ & 17 & 45 & 67 & 124 & .060 & .953 \\
\hline $\begin{array}{l}\text { Asking students to think and argue about the learning } 253 \\
\text { material. }\end{array}$ & 3 & 67 & 97 & 86 & .051 & .808 \\
\hline Asking students to critically analyses the learning content 253 & 13 & 78 & 95 & 67 & .055 & .872 \\
\hline Structuring all concepts/ topics as cause and effect & 12 & 83 & 92 & 66 & .055 & .869 \\
\hline $\begin{array}{l}\text { Let the students decide about learning experiences within } 253 \\
\text { set parameters. }\end{array}$ & 6 & 105 & 74 & 68 & .054 & .863 \\
\hline
\end{tabular}

Data in Table 1 show that the majority of the teachers always make connections between the topics and Compel students to learn through observation and senses. While the other instructional approaches Asking students to think and argue about the learning material, Asking students to critically analyses the learning content, Structuring all concepts/topics as cause and effect, Let the students decide about learning experiences within set parameters were found on average.

Table 2: Descriptive statistics of instructional approaches associated with "Evaluate" dimension

\begin{tabular}{lllllllll}
\hline & \multicolumn{4}{l}{ Frequency } & & \\
\cline { 5 - 7 } Teaching Methodologies related to Evaluate & $\mathrm{N}$ & In free & Sometimes Frequency Alway & Mean & Std. Dev \\
\hline Providing books about a variety of topics. & 253 & 28 & 61 & 72 & 92 & 2.90 & 1.021 \\
Asking students opinions & 253 & 19 & 82 & 81 & 71 & 2.81 & .933
\end{tabular}




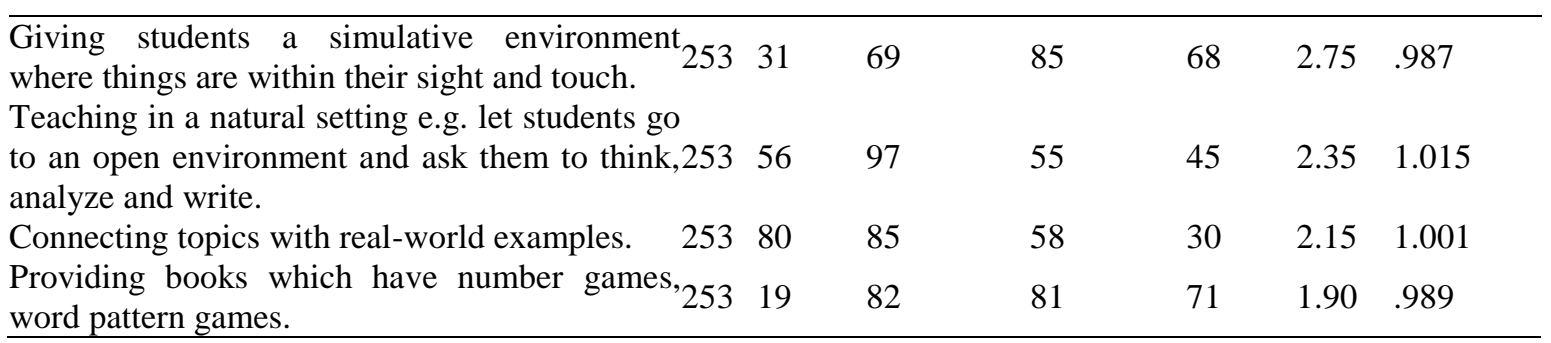

Table-2 reveals that majority of the teachers always provide books/link about a variety of topics, and ask students opinions but Giving students a simulative environment where things are within their sight and touch, Teaching in a natural setting e.g. let students go to an open environment and ask them to think, analyze and write. Connecting topics with real-world examples and provide books that have number games, word pattern games on the average.

Table 3: Descriptive statistics of instructional approaches associated with "Create" dimension

\begin{tabular}{|c|c|c|c|c|c|c|c|}
\hline & & Frequ & ency & & & & \\
\hline & $\mathrm{N}$ & Infra & Som & e Frequent & Alway & Mean & Dev \\
\hline $\begin{array}{l}\text { Using emotions when teaching (e.g. getting excited about } \\
\text { concept, indicating sadness over a sad story, etc.) }\end{array}$ & $a_{253}$ & 21 & 68 & 70 & 94 & 2.94 & 986 \\
\hline During Teaching, Insert Multiple character & 253 & 14 & 95 & 83 & 61 & 2.75 & .884 \\
\hline Teach the important complex topics in the form of a story. & 253 & 15 & 117 & 61 & 60 & 2.66 & 907 \\
\hline Relate specific topics with sounds and rhymes & 253 & 147 & 60 & 22 & 24 & 1.70 & 979 \\
\hline $\begin{array}{l}\text { Asking students to bring the topic in creative form e } \\
\text { concept mapping }\end{array}$ & & 154 & 57 & 21 & 21 & 1.64 & .948 \\
\hline $\begin{array}{l}\text { I allow students to use their stuff for learning content (e. } \\
\text { paper, digital media, books, etc.) }\end{array}$ & 253 & 144 & 67 & 33 & 9 & 1.63 & .842 \\
\hline
\end{tabular}

Table-3 illustrates that teachers always Using emotions when teaching (e.g. getting excited about a concept, indicating sadness over a sad story, etc.) but on the average Insert Multiple characters, Teach the important complex topics in the form of a story, Relate specific topics with sounds and rhymes, Asking students to bring the topic in the creative form e.g. concept mapping, I allow students to use their stuff for learning content (e.g. paper, digital media, books, etc.)

\section{Blooms Taxonomy Lower Order Thinking}

Table 4: Descriptive statistics of instructional approaches associated with "Remember" dimension

\begin{tabular}{|c|c|c|c|c|c|c|}
\hline & & Frequ & ency & & & \\
\hline $\begin{array}{ll}\mathrm{N} \\
\end{array}$ & Infrequ & Sometime & Frequ & ueAlway & Mean & Std. Dev \\
\hline $\begin{array}{l}\text { I help students to understand how everything they } \\
\text { learn is related to them. }\end{array}$ & 14 & 43 & 97 & 99 & 3.11 & .879 \\
\hline I recap the concepts after lecture & 13 & 78 & 95 & 67 & 2.85 & .872 \\
\hline $\begin{array}{l}\text { After teaching a concept, I provide time to students to } \\
\text { close their eyes and visualize what they have just read } 253 \\
\text { or learned. }\end{array}$ & 38 & 88 & 73 & 54 & 2.57 & .988 \\
\hline $\begin{array}{l}\text { I ask students to draw pictures of the material they } \\
\text { have learned (e.g. making spelling words into pictures, } 253 \\
\text { drawing images of their vocabulary words, etc.) }\end{array}$ & 43 & 83 & 69 & 58 & 2.56 & 1.024 \\
\hline $\begin{array}{l}\text { I bring in resource people who offer additional } \\
\text { perspectives on a topic. }\end{array}$ & 71 & 86 & 65 & 31 & 2.22 & .991 \\
\hline $\begin{array}{l}\text { I show videos to accompany the material being } 253 \\
\text { learned. }\end{array}$ & 115 & 56 & 58 & 24 & 1.96 & 1.033 \\
\hline
\end{tabular}

Table-4 illustrates that teachers always help students to understand how everything they learn is related to them and frequently recap the concepts after lecture but they use the other institutional approaches on the average.

Table 5: Descriptive statistics of instructional approaches associated with "Understand" dimension

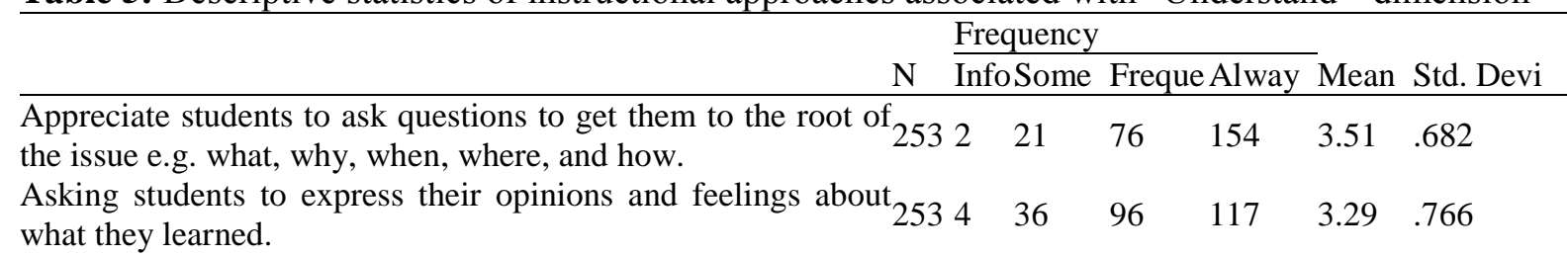


Analyze Evaluate Create Remember Understand Apply

\begin{tabular}{|c|c|c|c|c|c|}
\hline $\begin{array}{l}\text { Asking students to respond to instruction by using their bodies } 2534 \\
\text { as a medium of expression. }\end{array}$ & 54 & 85 & 110 & 3.19 & .823 \\
\hline $\begin{array}{l}\text { I discuss how topics are important to the classroom, school, } 2538 \\
\text { community, or world. }\end{array}$ & 65 & 82 & 98 & 3.07 & .877 \\
\hline $\begin{array}{l}\text { Providing an opportunity to share questions, answers, and } 25319 \\
\text { information with other students. }\end{array}$ & 51 & 81 & 102 & 3.05 & .952 \\
\hline $\begin{array}{l}\text { I make student groups work cooperatively towards common } \\
\text { instructional goals and develop projects. }\end{array}$ & 75 & 82 & 81 & 2.91 & .921 \\
\hline
\end{tabular}

Table-5 shows that majority of the teachers always Appreciate students to ask questions to get them to the root of the issue e.g. what, why, when, where and how and Asking students to express their opinions and feelings about what they learned Asking students to respond to instruction by using their bodies as a medium of expression but the other instructional approaches are used on the average.

Table 6: Descriptive statistics of instructional approaches associated with "Apply" dimension

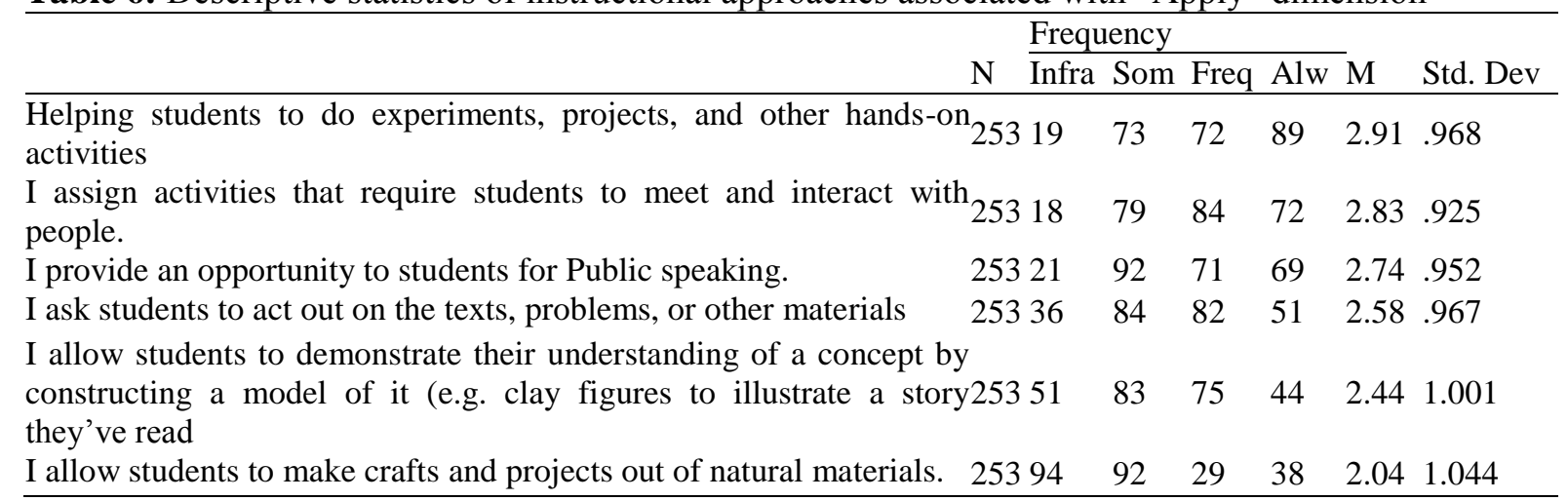

Table-6 shows that helping students to do experiments, projects, and other hands-on activities and assign activities that require students to meet and interact with people while the other instructional approaches were found used on average.

Bar Graph 1: Mean of the instructional approaches associated with revised blooms taxonomy six domains

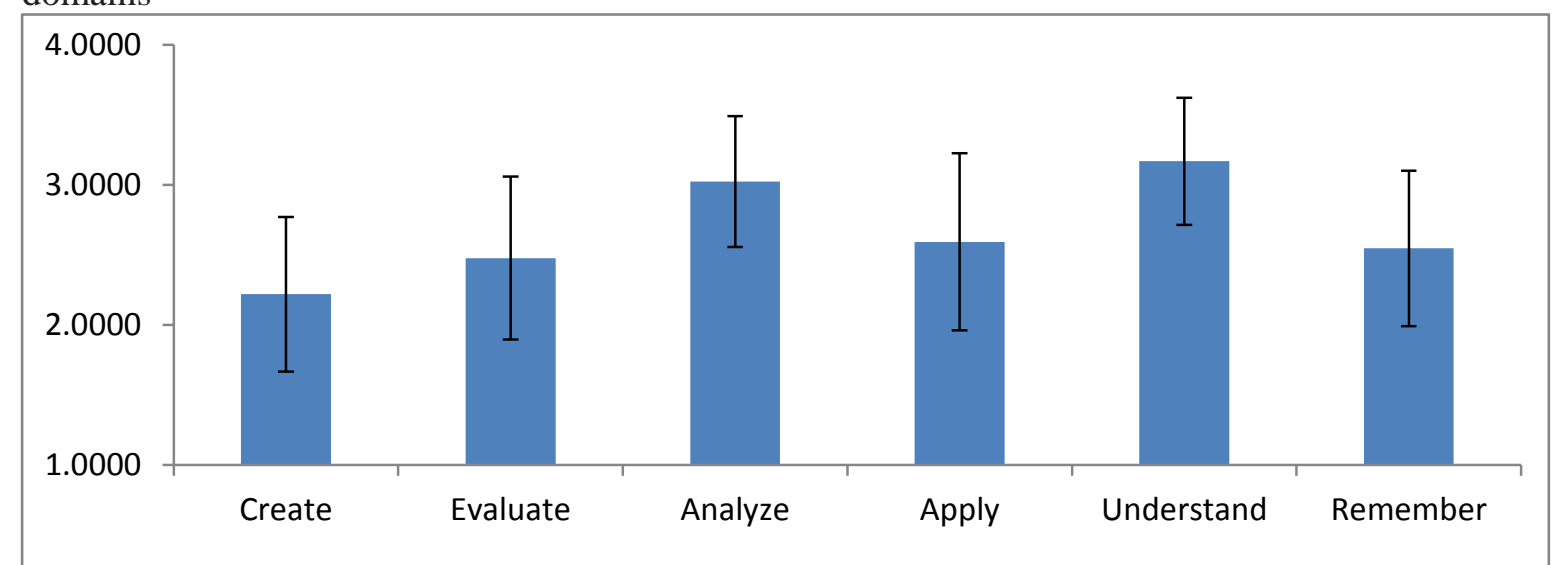

The bar graph-1 illustrates that among the Mean of the instructional approaches associated with revised blooms taxonomy six domains, the mean of the instructional approaches associated with Understand domain is high( $\mathrm{M}=3.6)$, accompanied by the instructional approaches linked with "Analysis" domain $(M=3.02)$. Similarly, the means for instructional approaches linked with "Remember" "Apply" and "Evaluate" were found as $\mathrm{M}=2.5, \mathrm{M}=2.5$, and $\mathrm{M}=2.4$ respectively. The lowest mean was observed for instructional approaches linked with the "Create" domain which was observed as $M=2.2$. It means teachers are using these two domains at a greater level, While the other on the average.

Correlational analysis of teachers' professional qualification and teaching experience on the incorporation of bloom taxonomy in Instructional methods

Table 7: Correlation Analysis 


\begin{tabular}{llllllll}
\hline Academic & Pearson Correlation & .059 & $.184^{* *}$ & $.148^{*}$ & .065 & .123 & .107 \\
Qualification & Sig. (2-tailed) & .349 & .003 & .019 & .300 & .051 & .091 \\
& $\mathrm{~N}$ & 253 & 253 & 253 & 253 & 253 & 253 \\
Teaching & Pearson Correlation & $-.147^{*}$ & $-.248^{* *}$ & -.104 & $-.277^{* *}$ & -.016 & -.101 \\
Experience & Sig. (2-tailed) & .019 & .000 & .098 & .000 & .796 & .108 \\
& $\mathrm{~N}$ & 253 & 253 & 253 & 253 & 253 & 253 \\
\hline
\end{tabular}

The value of Pearson correlation coefficient results of the instructional approaches linked with analysis $(\mathrm{r}=+.059)$, evaluate $(\mathrm{r}=+.184)$, create $(\mathrm{r}=+.148)$, remember $(\mathrm{r}=+.065)$, understand $(\mathrm{r}=$ $+.123)$, and apply $(\mathrm{r}=+.107)$, show a positive but very weak correlation with the academic qualification of the teachers. While the teaching experience was observed as having no impact on teachers preferences for incorporating the different domains of bloom's taxonomy in their instruction.

\section{Discussion}

Teaching Methods have had a significant influence on student behaviors (Entwistle and Entwistle, 1992). Researches have argued that teaching is the best way of improving this relationship in the process of developing courses and learning outcomes (Wiggins and McTighe, 1998; Pellegrino et al., 1999; Fink, 2003). Bringing Cognitive approaches in teaching has been found improving learning that is geared to learners as well as cultivating sophisticated critical thinking skills (Rivard, 1994). It is a difficult task to use methods that encourage students to think, excel and promote cognitive needs. Revised bloom taxonomy facilitates teachers to nourish the cognitive skills of the students.

In the present study teachers' preferences in their instructional methods were integrated with the revised model of blooms taxonomy to seek out how much they are incorporating the instructional approaches linked with all six domains of revised bloom taxonomy. The study has also sought out the impact of teachers' qualifications and teaching experiences on teachers' preferences for these instructional approaches. The findings show that teachers often use the higher-order domain, while other large domains were found on average. This may be due to the existing system of board examination. As mentioned by Iqbal et al, (2008), board examinations are often evaluated at lower cognitive levels, teachers thus prefer methodologies that only cultivate lower-level cognitive skills.

One reason for this divergence is the possibility that secondary school teachers may not have received the instruments and guidelines to help them align their teaching with the students ' cognitive abilities. The other reasons may be due to the current trend of growing size and decreasing funding for assists, short class times and insufficient resources available for teachers to help with this effort (Schraw, 1998; Bransford, et al., 2000; Pintrich, 2001; D'Avanzo, 2003; Coutinho, 2007).

In light of the findings, the study suggests that teachers spend their time designing teaching methodologies that can promote higher-level thought skills for students, to improve their student learning qualifications. Teachers can adopt methodologies to enable their students to think and discuss the content, encourage discussion, stimulate students to find information themselves, create cause and effect, encourage student opinion, insert several characters and map concepts in the real world. Besides, additional teaching support can also be expected from departments and administrations.

The study recommends that teachers make their students think and analyze the material, establish cause and effect, promote students' thoughts, examples from the environment, introduce multiple characters, map concepts and allow students to make books in another way. The study suggests teachers follow Bloom's cognitive dimensions to develop their teaching techniques in future classes. Because of the experience and recorded significance of metacognition in all disciplines of student research (Schraw, 1998; Bransford et al. , 2000; Pintrich, 2002; D'Avanzo, 2003; Coutinho, 2007). Using teachers' RBT will help students gain a deeper insight into the principles and skills required for a good career. More work may also concentrate on the symbiotic link between educational design and cognitive fields. Meanwhile, the empirical base of Bloom's Taxonomy and its work in the promotion of cognitive complexity provide a solid basis for his application in advisor education at the postgraduate level.

\section{References}

Schraw, G. (1998). Promoting general metacognitive awareness. Instructional Science, 26(1-2), 113125.

Bransford, J. D., Brown, A. L., \& Cocking, R. R. (2000). How people learn (Vol. 11). Washington, DC: National academy press. 
Pintrich, P. R. (2002). The role of metacognitive knowledge in learning, teaching, and assessing. Theory into Practice, 41(4), 219-225.

Domenighetti, G., D’Avanzo, B., Egger, M., Berrino, F., Perneger, T., Mosconi, P., \& Zwahlen, M. (2003). Women's perception of the benefits of mammography screening: a population-based survey in four countries. International journal of epidemiology, 32(5), 816-821.

Schraw, G. (1998). Promoting general metacognitive awareness. Instructional Science, 26(1-2), 113125.

Bransford, J. D., Brown, A. L., \& Cocking, R. R. (2000). How people learn (Vol. 11). Washington, DC: National academy press.

Wiggins, G., \& McTighe, J. (1998). What is backward design? Understanding by design, 1, 7-19.

Cho, J., Amy, G., \& Pellegrino, J. (1999). Membrane filtration of natural organic matter: initial comparison of rejection and flux decline characteristics with ultrafiltration and nanofiltration membranes. Water Research, 33(11), 2517-2526.

Halligan, P. W., Fink, G. R., Marshall, J. C., \& Vallar, G. (2003). Spatial cognition: evidence from visual neglect. Trends in cognitive sciences, 7(3), 125-133.

Noble, E. E., Mavanji, V., Little, M. R., Billington, C. J., Kotz, C. M., \& Wang, C. (2014). Exercise reduces diet-induced cognitive decline and increases hippocampal brain-derived neurotrophic factor in CA3 neurons. Neurobiology of learning and memory, 114, 40-50.

MacLullich, A. M. J., Ferguson, K. J., Deary, I. J., Seckl, J. R., Starr, J. M., \& Wardlaw, J. M. (2002). Intracranial capacity and brain volumes are associated with cognition in healthy elderly men. Neurology, 59(2), 169-174.

MacLullich, A. M. J., Ferguson, K. J., Deary, I. J., Seckl, J. R., Starr, J. M., \& Wardlaw, J. M. (2002). Intracranial capacity and brain volumes are associated with cognition in healthy elderly men. Neurology, 59(2), 169-174.

Ferguson, K. J., MacLullich, A. M., Marshall, I., Deary, I. J., Starr, J. M., Seckl, J. R., \& Wardlaw, J. M. (2002). Magnetic resonance spectroscopy and cognitive function in healthy elderly men. Brain, 125(12), 2743-2749.

Krathwohl, D. R. (2002). A revision of Bloom's taxonomy: An overview. Theory into Practice, 41(4), 212-218.

Anderson, L. W. (1999). Rethinking Bloom's Taxonomy: Implications for Testing and Assessment.

Krathwohl, D. R., \& Anderson, L. W. (2009). A taxonomy for learning, teaching, and assessing: A revision of Bloom's taxonomy of educational objectives. Longman.

Scouller, K. (1998). The influence of assessment method on students' learning approaches multiple choice question examination versus assignment essay. Higher Education, 35(4), 453-472.

Wiggins, G., \& McTighe, J. (1998). What is backward design? Understanding by design, 1, 7-19.

Sundberg, J. (1999). Cognitive Aspects of Music Performance. Music and signs. Semiotic and Cognitive Studies in Music, 1, 219-230.

Ebert-May, D., Derting, T. L., Henkel, T. P., Middlemis Maher, J., Momsen, J. L., Arnold, B., \& Passmore, H. A. (2015). Breaking the cycle: Future faculty begin teaching with learnercentered strategies after professional development. CBE—Life Sciences Education, 14(2), $\operatorname{ar} 22$.

Halligan, P. W., Fink, G. R., Marshall, J. C., \& Vallar, G. (2003). Spatial cognition: evidence from visual neglect. Trends in cognitive sciences, 7(3), 125-133.

Momsen, J. L., Long, T. M., Wyse, S. A., \& Ebert-May, D. (2010). Just the facts? Introductory undergraduate biology courses focus on low-level cognitive skills. CBE-Life Sciences Education, 9(4), 435-440.

Lemons, P. P., \& Lemons, J. D. (2013). Questions for assessing higher-order cognitive skills: It's not just Bloom's. CBE—Life Sciences Education, 12(1), 47-58.

Tomlinson, P. (1999). Conscious reflection and implicit learning in teacher preparation. Part I: Recent light on an old issue. Oxford Review of Education, 25(3), 405-424.

Handelsman, Y. (2009). Metabolic syndrome pathophysiology and clinical presentation. Toxicologic Pathology, 37(1), 18-20.

Foreman, M. D., Fletcher, K., Mion, L. C., \& Trygstad, L. (2003). Assessing cognitive function. Geriatric Protocol for Best Practice, 99-115. 
Stainback, K. (2007). Discrimination and desegregation: Equal opportunity progress in US private sector workplaces since the Civil Rights Act. The annals of the American academy of political and social science, 609(1), 49-84. 